\title{
Induced migration of fines during waterflooding in communicating layer-cake reservoirs
}

\author{
Yuan, Hao; Shapiro, Alexander
}

Published in:

Journal of Petroleum Science and Engineering

Link to article, DOI:

10.1016/j.petrol.2011.08.003

Publication date:

2011

Document Version

Early version, also known as pre-print

Link back to DTU Orbit

Citation (APA):

Yuan, H., \& Shapiro, A. (2011). Induced migration of fines during waterflooding in communicating layer-cake reservoirs. Journal of Petroleum Science and Engineering, 78(3-4), 618-626.

https://doi.org/10.1016/j.petrol.2011.08.003

\section{General rights}

Copyright and moral rights for the publications made accessible in the public portal are retained by the authors and/or other copyright owners and it is a condition of accessing publications that users recognise and abide by the legal requirements associated with these rights.

- Users may download and print one copy of any publication from the public portal for the purpose of private study or research.

- You may not further distribute the material or use it for any profit-making activity or commercial gain

- You may freely distribute the URL identifying the publication in the public portal

If you believe that this document breaches copyright please contact us providing details, and we will remove access to the work immediately and investigate your claim. 


\section{Accepted Manuscript}

Induced migration of fines during waterflooding in communicating layer-cake reservoirs

Hao Yuan, Alexander A. Shapiro

PII: S0920-4105(11)00193-8

DOI: doi: $10.1016 /$ j.petrol.2011.08.003

Reference: $\quad$ PETROL 2089

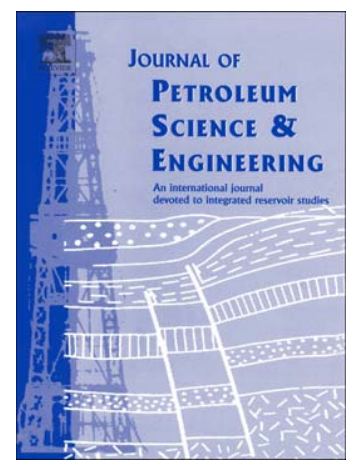

To appear in: $\quad$ Journal of Petroleum Science and Engineering

Received date: $\quad 13$ April 2011

Accepted date: $\quad 8$ August 2011

Please cite this article as: Yuan, Hao, Shapiro, Alexander A., Induced migration of fines during waterflooding in communicating layer-cake reservoirs, Journal of Petroleum Science and Engineering (2011), doi: 10.1016/j.petrol.2011.08.003

This is a PDF file of an unedited manuscript that has been accepted for publication. As a service to our customers we are providing this early version of the manuscript. The manuscript will undergo copyediting, typesetting, and review of the resulting proof before it is published in its final form. Please note that during the production process errors may be discovered which could affect the content, and all legal disclaimers that apply to the journal pertain. 


\title{
Induced Migration of Fines during Waterflooding in
}

\section{Communicating Layer-cake Reservoirs}

\author{
Hao Yuan*, Alexander A. Shapiro \\ CERE - Center for Energy Resources Engineering, Technical University of Denmark, DTU \\ Building 229, 2800 Lyngby, Denmark.Email hy@kt.dtu.dk
}

\begin{abstract}
The effects of fines migration induced by injection of water with a different salinity than the reservoir brine are incorporated into the upscaling model for waterflooding in a layer cake reservoir with good communication between the layers. Mobilization and re-capturing of the reservoir fines may give rise to reduction of the permeability in water swept zones, which subsequently leads to the diversion of water flow from the initially more permeable layers to the less permeable ones. As a result, the displacement is more even, the water cut at the producer is decreased, and the oil recovery is increased. On the other hand, more energy for the pressure drop is required to maintain a constant flow rate. These effects are studied within a new upscaling model developed previously (Zhang et al., 2011). In a communicating layer cake reservoir, higher end-point mobility ratio (water to oil) leads to more crossflow between layers and lowers the water sweep efficiency. However, this ratio facilitates the fluid diversion caused by the fines migration, leading to a more efficient enhanced oil recovery. The positive contribution from the mobility ratio to the increased oil recovery due to fines migration seems to be limited.
\end{abstract}

Keywords: low salinity waterflooding, fines migration, layer-cake reservoir, crossflow, enhanced oil recovery 


\section{Introduction}

Migration of reservoir fines and subsequent permeability decline has been widely observed in core flooding experiments under various conditions (Bernard, 1967; Fauré et al., 1997; Lever and Dawe, 1987; Mungan, 1965; Mohan et al., 1993). There is a considerable and ongoing effort aimed at understanding the release, the relocation, and the recapture of reservoir fines. It is usually suggested that such phenomena should be avoided due to its detrimental effects on the permeability and pressure drop. Nevertheless, it can also be considered as a mobility control method for improving waterflooding performance. An induced reduction in the effective mobility of water by the migration of reservoir fines in water swept zones may increase the sweep efficiency of water. This process is similar to the mechanisms of other EOR mobility control techniques, such as polymer flooding.

It has been observed in a number of works that the composition of the injected brine influences significantly the release and relocation of the reservoir fines (Sharma and Yortsos, 1987; Tang and Morrow, 1999; Valdya and Fogler, 1992). The release of fines is affected by salinity, pH, temperature, and velocity of the pore water. The effects of water composition on wettability, relative permeability, capillary pressure, and residual oil saturation were investigated, along with the migration of reservoir fines (Rivet et al., 2010; Tang and Morrow, 1999; Valdya and Fogler, 1992; Yildiz and Morrow, 1996). The migration of reservoir fines appears to be a separate phenomenon but occurs simultaneously with other effects.

Injection of low salinity water into a saturated core of high salinity has been observed to give rise to significant reduction of permeability owing to the migration and the recapture of clay fines (Fauré et al., 1997; Fogden et al., 2011; Lever and Dawe, 1987; Mohan et al., 1993; Ryan and Gschwend, 1994; Sharma and Yortsos, 1987). There exists a critical salt concentration (CSC) below which the clay particles start to release. The release and relocation of the reservoir fines are almost instantaneous. Since water of low salinity is usually readily available, or easy to produce, reducing the salinity of the injected water is likely to be the most practical method to implement 
mobility control compared to other alternatives controlling the migration of reservoir fines, such as the $\mathrm{pH}$, or the temperature of water.

Several models for the release of deposited particles in porous media were proposed on the basis of detachment kinetics (Bradford et al., 2003; Bradford et al., 2006; Bradford et al., 2009; Grolimund and Borkovec, 2001; Shapiro and Stenby, 2000; Yuan and Shapiro, 2011), while the maximum retention model assumed instantaneous release of particles which are available to detach under the given condition (Bedrikovetsky et al., 2010; Zeinijahromi et al., 2011). These kinetics-based models exhibited a delayed response to an abrupt velocity increase or salinity decrease, which disagreed with the almost instantaneous response in the experiments (Mungan, 1965; Mohan et al., 1993; Ochi and Vernoux, 1998). The maximum retention model, on the other hand, exhibited response without delay (Bedrikovetsky et al., 2010; Lemon et al., 2011) and was chosen for the current study.

In the work of Zeinijahromi et al.(2011) the maximum retention function was incorporated into the Dietz model for waterflooding in a non-communicating layer-cake reservoir. Initially deposited fines were assumed to be released instantaneously due to the injection of low-salinity water. The released fines might be recaptured via straining at pore throats and cause the reduction of permeability in the water swept zones. Introduction of these effects allowed for the re-definition of the pseudo fraction flow function and led to lower relative mobility of water. The breakthrough time of water was increased while the water cut at the production well was decreased.

The current study proceeds from the previous works on induced migration of reservoir fines and investigates these effects during low salinity waterflooding in a communicating layer-cake reservoir. First, the maximum retention as a function of both the salinity and the velocity of the injected water is introduced (Bedrikovetsky et al., 2010; Zeinijahromi et al., 2011). The concepts 
behind the use of induced fines migration for mobility control are explained. Then the upscaling model for waterflooding in a communicating layer cake reservoir (Yortsos, 1995; Zhang et al., 2011 ) is adapted to incorporate the effects of fines migration. Finally, sample calculations are carried out to investigate such effects on the water saturation profiles, the pressure drop, the water cut at the production well, and the recovery.

\section{Induced fines migration by alteration of injected water chemistry}

The balance of the hydrodynamic torque, the lifting torque, the resisting adhesive torque and the torque of gravity determines whether the reservoir fines attaching to the pore walls will be immobilized and re-entrained into the carrying fluid (Bergendahl and Grasso, 2000; Bedrikovetsky et al., 2010; Jiao and Sharma, 1994; Schembre and Kovscek, 2004; Sharma and Yortsos, 1987; Torkzaban et al., 2007).The erosion number, a dimensionless parameter indicating the ratio between the torques for the detachment and the attachment of particles, can be expressed in the following way:

$$
\varepsilon=\frac{F_{l} l_{n}+F_{d} l_{d}}{\left(F_{e}+F_{g}\right) l_{n}}
$$

where $F_{l}, F_{d}, F_{e}$, and $F_{g}$ are respectively the lifting force, the hydrodynamic drag, the

electrostatic force, and the gravity exerting on the particles attached to the pore walls. $l_{d}$ and $l_{n}$ are respectively the levers of drag and normal forces. The forces and their moments on the particles attached to the internal cake surface are illustrated in Fig. 1.

Particles are released instantly and re-entrained into the carrying fluids if the torque for detachment is larger than that for attachment, i.e. the value of the erosion number is greater than 
one. It is shown by Bedrikovetsky et al. (2010) that the maximum retention is a function of the erosion number:

$$
\sigma=\sigma_{c r}(\varepsilon)
$$

where $\sigma$ is the concentration of retained particles $\left(\mathrm{m}^{3} / \mathrm{m}^{3}\right)$. The physical meaning of the maximum retention function can be interpreted as follows. Given a certain setting of injected water chemistry and velocity there exists a maximum retained amount of the particles, above which the excess deposited particles are released. Below the maximum retention the torques from the lifting and the hydrodynamic drag are insufficient to overcome the torques from the electrostatic force and the gravity. The rise of pore water velocity increases the lifting force and the hydrodynamic drag, while the decrease of water salinity reduces the adhesive torque.

Consequently, water velocity, salinity, $\mathrm{pH}$, temperature and other properties of water chemistry may all be influential on the value of the maximum retention.

It may be assumed that the re-entrained particles are recaptured instantly at the neighboring pore throats via physical straining. The recaptured particles are assumed not to be released due to the change of water chemistry or velocity, since the deposition mechanisms are different from the surface attachment. The total amount of the released particles equals to the sum of the particles captured at pore throats and the effluent ones. In the case of media with thin pore throats, we may assume that all the released particles are instantly re-captured via straining:

$$
\sigma_{i n i}=\sigma_{c r}(\varepsilon)+\sigma_{s t r}
$$

where the subscripts 'ini' represents the amount of deposited particles at the initial condition, and 'str' represents straining.

Following Refs. (Bachman et al., 2003; Mojarad and Settari, 2007; Pang and Sharma, 1997), it is assumed that the inverse to normalized permeability $k / k_{0}$ is a linear function of retained particle 
concentration. It is also assumed that the detachment of a particle attaching to the pore walls causes a negligible increase in permeability, while plugging of pore throats via straining causes a significant permeability reduction:

$$
\frac{k_{0}}{k}=1+\beta \sigma_{s t r}
$$

where $k$ is the permeability, $\beta$ is the formation damage coefficient. Since the migration of reservoir fines may only occur in the water swept zones, the effects of permeability damage should only be taken into account for water flow. It is therefore reasonable to assume the reduction of the relative permeability of water can be described by a similar expression as Eq. (4).

The above considerations are sufficient for the inclusion of the induced fines migration and subsequent permeability reduction into a reservoir simulation model. Pore plugging of the released reservoir fines works as a fluid diversion mechanism. The reduction of the permeability in the water swept zones may retard the propagation of water fingers and increase the sweep efficiency. Similar mobility control techniques, such as polymer injection, may be applied to reduce the mobility ratio and decrease the fraction flow of water.

\section{Upscaling waterflooding in communicating layer-cake reservoirs}

The upscaling method proposed by Yortsos (1995) and Zhang et al. (2011) was applied to investigate influence of fines migration on the performance of waterflooding in communicating layer cake reservoirs. The main assumption underlying the upscaling model is that the gradient of the pressure drop in vertical direction may be set zero due to high anisotropy aspect ratios. As a result, the mass communication between neighboring layers in the vertical direction is instantaneous. 
In this work, it is assumed that water is injected into a two dimensional rectangle reservoir from one side to the other at a constant flow rate. The top and bottom of the reservoir is insulated with impermeable boundaries. Detailed model formulations can be found in Appendix A.

\section{Adapted models for fines migration and waterflooding}

In this section, the maximum retention model for fines migration is incorporated in the upscaling model for waterflooding in communicating layer-cake reservoirs. Both reduction of the permeability due to pore plugging and the subsequent diversion of fluids flow across different layers are taken into account.

Migration of fines causing the reduction of the permeability in the vertical direction is neglected, since perfect communication between the reservoir layers is assumed in this work. The maximum retention model (Bedrikovetsky et al., 2010) is developed in the framework of single water phase flow. The application of such a model for the waterflooding in an oil reservoir requires more considerations for the spatial distribution of the two immiscible phases. In a water-wet porous medium, due to the capillary pressure and the median wettability, water is inclined to flow along the pore walls, around median grain constrictions and in the smaller pores (Barenblatt et al., 1990; Barenblatt et al., 2003 , Schembre and Kovscek, 2004). Under such assumptions the flow of water causing the hydrodynamic drag can be expressed via the fraction of the total flow rate:

$$
v_{w}=\frac{f(s) U}{\varphi_{S}}
$$

where $v_{w}$ is the pore velocity of the water phase, $U$ is the total Darcy's velocity, $f(s)$ is the fraction flow of water, $\varphi$ is the porosity, and $s$ is the water saturation. More detailed 
considerations for the particle and pore size distributions are possible, while it is beyond the scope of the current work (see the works of Shapiro et al. (2007), Shapiro and Bedrikovetsky (2010), Yuan and Shapiro (2010, 2011)) for the distributed flow modeling). Eq. (5) serves as a simplified assumption. It is also assumed that the presence of small amount of residual oil does not change the process of particle release significantly and can be neglected. This assumption probably needs further refinement in the future work (see experimental evidence from Fogden et al. (2011)). With this modification, the expression of the erosion number in Eq. (1) may be rewritten as (detailed derivations can be found in Appendix B):

$$
\varepsilon=\frac{\mu_{w} r_{s}^{2} f(s) U}{s \sqrt{k \varphi} F_{n}}
$$

where $\mu_{w}$ is the viscosity of water, $r_{s}$ is the particle radius, and $F_{n}$ is the normal force exerting on the particles (lifting force, gravity, and electrostatic force). With the consideration of Eq. (4), the total mobility in the $i$ th layer and the fraction flow of water can be written as (details can be found in Appendix C):

$$
\lambda_{x i}=\left(\frac{\lambda_{r w i}}{1+\beta \sigma_{s t r}}+\lambda_{r o i}\right), \quad f_{i}=\frac{\lambda_{r w i} /\left(1+\beta \sigma_{s t r}\right)}{\lambda_{r w i} /\left(1+\beta \sigma_{s t r}\right)+\lambda_{r o i}}
$$

where $\lambda_{x}$ is the horizontal mobility, $\lambda_{r w}$ and $\lambda_{r o}$ are the relative mobility of water and oil, index ' $i$ ' represents the $i$ th horizontal reservoir layer.

The adapted waterflooding model assumes that the salt $(\mathrm{NaCl})$ behaves as a neutral additive in the reservoir, namely the influence of salt concentration on water viscosity and the adsorption/desorption of salt on pore surface are ignored. It is assumed that the salt in the connate water before the displacement front is immobile and that the dispersion/diffusion of salt is negligible. Such assumptions can ensure that the low-salinity front travels at the same velocity as 
the water front (Lake, 1989, Bedrikovetsky, 1993). The ratio between the tracer and water front velocities usually ranges from 1:1.1 to 1:1.4 in practice which justifies the above assumptions (Lemon et al., 2011, Zeinijahromi et al., 2011). The model also assumes that the change in the composition of the injected water due to mixing with the connate water is negligible. As a result, the alteration of salinity and consequent permeability decline occurs instantly after the water front passes a given point of the reservoir, leading to Eq. (7). The above assumptions also allow us to reduce the equation for the mass balance of salt.

Due to the assumption of instant straining of all released particles, the concentration of strained particles is equal to the initial deposition minus the maximum retention. The maximum retention is dependent on the local velocity of water, which leads to the dependence of strained retention on water velocity:

$$
\sigma_{s t r}=\sigma_{i n i}-\sigma_{c r}\left(\frac{\mu_{w} r_{s}^{2} f(s) U_{i}}{s \sqrt{k_{x} \varphi} F_{n}}\right)
$$

Similar to the models for fines migration in non-communicating layer-cake reservoirs (Zeinijahromi et al., 2011), the model in this work is also indicative only. The model focuses on the effects of fines migration in the communicating layer-cake reservoirs specifically. Injection of low salinity water is only one example to induce the migration of reservoir fines, while other alternatives may also result in fines migration, such as $\mathrm{pH}$. The model does not take into account other effects of the injection of low salinity water, such as the alteration of capillary pressure, residual oil saturation, and pore size distribution (Bernard, 1967; Mungan, 1965; Shapiro et al., 2007; Shapiro and Bedrikovetsky, 2010). The proposed model, under the assumption of constant residual oil saturation, may underestimate the benefit of low salinity water injection in a communicating layer cake reservoir. 
One key assumption of this model is that the hydrodynamic drag from the fluid is assumed to be only from the water phase. As a result, the maximum retention function is dependent on the water saturation. Such an assumption is reasonable for completely water-wetted rocks where water flows along pore surface and around constrictions. For partially wetted or oil-wetted rocks where the wetted pore surface also depends on water saturation, the current model can be extended to account for the available fines for release depending on water saturation. Such effects are currently beyond the scope of this study.

\section{Results and discussions}

In this section, sample calculations are carried out to investigate the effects of fines migration on the water saturation profiles, the pressure drop, the water cut at the production well, and the recovery for a given flow rate.

It is assumed that a reservoir consisting of 30 horizontal layers is flooded with water of low salinity into one side, and oil is produced on the other side. The top and the bottom of the reservoir are insulated with impermeable boundaries. The horizontal permeabilities of different layers are assumed to follow a discrete log-normal distribution. The mean value and the standard deviation of the logarithm of dimensionless permeability are 1.0 and 0.1 respectively. The minimum of the dimensionless permeability is set to be 0.5 , and the maximum is selected in such a way that the mean dimensionless permeability $\langle K\rangle=1.0$. The following properties of fluids are adopted: $s_{w i}=0.1, s_{o r}=0.3, \mu_{w}=1 \mathrm{cP}, \mu_{o}=2 \mathrm{cP}, \alpha_{w}=2, \alpha_{o}=2, \mathrm{k}_{r w o r}=0.8, \mathrm{k}_{\text {rowi }}=0.4$. For the calculations of the maximum retention, the properties of sandstones are taken from the laboratory tests of low salinity waterflooding (Lever and Dawe, 1984): the average porosity $\varphi=0.1$, the average permeability $\left\langle k_{x}\right\rangle=100 \mathrm{mD}$. The initial deposition $\sigma_{i n i}=0.01$ (volume fraction). The radius of 
the deposited particles $r_{s}=1 \mu \mathrm{m}$, the density of the particle material $\rho_{p}=2 \times 10^{3} \mathrm{~kg} / \mathrm{m}^{3}$, the maximum electrostatic force $F_{e}=4 \times 10^{-11} \mathrm{~N}$, the lifting coefficient $\chi=89.5$, the coefficient for hydrodynamic drag $\omega=60$, the internal cake porosity $\varphi_{c}=0.5$. Details of the calculation for the maximum retention can be found in Appendix B.

\subsection{Effects of formation damage}

Calculations are carried out with different values of the formation damage coefficient $\beta$. Previous study on low-salinity waterflooding (Lever and Dawe, 1984; Zeinijahromi et al., 2011) are taken into account to select the values of $\beta$. Water saturation profiles at dimensionless time $T=0.1$ (measured in porous volumes injected) are revealed at the top, the horizontal center, and the bottom of the reservoir in Fig. 2. With larger values of the formation damage coefficient, the displacement fronts in the more permeable layers are more retarded, as seen in Fig.2 (a) and (b). The displacement front in the least permeable layer is accelerated, as seen in Fig.2 (c). The averaged water saturation profiles $(\xi=\mathrm{X} / \mathrm{T})$ are revealed in Fig. 3. It can be seen larger formation damage gives rise to more even displacement profiles. The water saturation profiles at $\mathrm{T}=0.1 \mathrm{in}$ the $\mathrm{X}-\mathrm{Z}$ plane are revealed in particular for $\beta=0$ and $\beta=150$ in Fig. 4 . The displacement fronts are clearly retarded in the more permeable layers (close to top), and accelerated in the less permeable layers (close to bottom).

Such phenomena are resulted from the fluid diversion mechanism in connection with the migration of reservoir fines. In water swept zones the reservoir fines in place are released due to the change of water chemistry. The released fines are instantly captured at the neighboring pore throats and reduce the relative permeability of water subsequently. As a result, water flow is diverted from more permeable layers to the less permeable layers. 
Water cut at the producer and the recovery factor are then calculated and plotted in Fig. 5. It can be seen that the breakthrough of water is delayed with larger values of the formation damage coefficient. After the first breakthrough of water in the most permeable layers, the breakthrough in the less permeable layers occurs and corresponds to the transition points ("corner points" in Fig.5 (a)). The breakthrough in the less permeable layers is earlier with larger values of $\beta$. As a result, the current recovery is increased due to less water flow at the production site.

The pressure drop between the injector and the producer, corresponding to a constant overall flow rate, is calculated and revealed in Fig. 6. It can be seen that the pressure drop decreases more slowly with more formation damage caused by the migration of reservoir fines. After $\beta$ exceeds a certain value (approximately $\beta=120$ ), the pressure drop becomes a non-monotonous function of time. It indicates that more energy is required due to the formation damage to maintain a constant flow rate.

The water saturation profiles indicate that the induced migration of reservoir fines is in favor of increasing water sweep efficiency. The resulting water cut and the recovery show that such phenomena may improve the waterflooding performance for oil production. Nevertheless, more energy is required to increase the pressure drop and maintain a constant flow rate.

\subsection{Effects of mobility ratios and crossflow}

Calculations are carried out with different values of the end-point mobility ratio $M=\left(k_{r w o r} \mu_{o}\right) /\left(k_{\text {rowi }} \mu_{w}\right)$. For the calculations of normal waterflooding $\beta=0$, for the calculations of low salinity waterflooding $\beta=50$. The viscosity ratio of water and oil is modified to obtain the different values of the mobility ratio $M$. 
Fig. 7 shows that low salinity waterflooding delays the breakthrough of water and increases the oil recovery for all the values of $M$. Larger mobility ratios, on the other hand, result in earlier breakthrough and lower oil recovery. The increased oil recovery due to migration of reservoir fines is larger with larger values of $M$, as seen in Fig. 8 (a). In the range of high mobility ratios, the increased oil recovery is much less sensitive to the mobility ratio, as seen in Fig. 8 (b). It seems that the positive contribution from the mobility ratio to the increased oil recovery due to fines migration is limited. Such phenomena may be explained by the enhanced effects of corssflow due to larger water-oil mobility ratios.

A more detailed explanation of the effect of the mobility ratio $M$ on the crossflow may be obtained along the following lines. Eq. (A-9) indicates that the driving force of crossflow is the difference of the horizontal gradients of accumulated mobility in different layers. The horizontal mobility gradient can be rewritten as a function of the mobility derivative with regard to water saturation, as seen in Eq. (9) below.

$$
\begin{aligned}
& \frac{\partial \Lambda_{x}}{\partial X}=\frac{d \Lambda_{x}}{d s} \frac{\partial s}{\partial X} \\
& \frac{d \Lambda_{x}}{d s}=K\left[\alpha_{o} \frac{\left(1-s-s_{o r}\right)^{\alpha_{o}-1}}{\left(1-s_{o r}-s_{w i}\right)^{\alpha_{o}}}+\frac{M}{1+\beta \sigma_{s t r}} \alpha_{w} \frac{\left(s-s_{w i}\right)^{\alpha_{w}-1}}{\left(1-s_{o r}-s_{w i}\right)^{\alpha_{w}}}\right]
\end{aligned}
$$

The values of $d \Lambda_{X} / d s$ are larger with larger values of $M . \partial \Lambda_{X} / \partial X$ is more sensitive to $\partial s / \partial X$ with larger $M$. As a result, the crossflow between layers is enhanced with larger values of the mobility ratio. It may facilitate the fluid diversion between layers caused by fines migration.

\section{Conclusions}

The effect of fines migration induced by injection of low salinity water has been incorporated into the upscaling model for waterflooding in a communicating layer cake reservoir. The torque 
balance on the deposited reservoir fines via attachment, the straining of released fines, the consequent permeability damage, and the cross-flow between layers have been taken into account.

Particle release and re-deposition give rise to the reduction of the permeability in water swept zones, which subsequently leads to the diversion of water flow from the more permeable layers to the less permeable ones. As a result, the water cut at the producer is decreased, and the oil recovery is increased. However, more energy for the pressure drop is required to maintain a constant flow rate. Modeling results have shown that higher formation damage coefficients (more permeability damage) give rise to later breakthrough of water, lower water cut, higher oil recovery, and higher pressure drop to maintain a constant flow rate.

In a communicating layer cake reservoir, higher end-point mobility ratio $M$ (water to oil) leads to more crossflow and lowers the water sweep efficiency. However, the effect of fluids diversion caused by fines migration is stronger in this case. The increased oil recovery due to fines migration increases with the mobility ratio in the range of low mobility ratios (2 4), while it is insensitive to the mobility ratio in the range of high mobility ratios $(>50)$. The positive contribution from the mobility ratio to the increased oil recovery due to fines migration seems to be limited. Thus, the enhanced oil recovery method, low salinity water flooding causing the migration of fines, is more efficient with larger mobility ratio in communicating layer-cake reservoirs. 


\section{Acknowledgement}

This work is funded by the Danish Council for Independent Research, Technology and Production Sciences (FTP), which is kindly acknowledged for financial support.

\section{Nomenclature}

\section{Nomenclature}

$F \quad$ Forces exerting on fines attached to pore surface

$H \quad$ Height of reservoir

$L \quad$ Length of reservoir

$k \quad$ Absolute permeability

$M \quad$ End-point mobility ratio of water to oil

$N \quad$ Number of layers

$s \quad$ Water saturation

$t \quad$ Time

$T \quad$ Dimensionless time/ pore volume injected

U Darcy's velocity

$x \quad$ Coordinate in the horizontal direction

$X \quad$ Dimensionless $x$

$z \quad$ Coordinate in the vertical direction

Z Dimensionless $z$

$f \quad$ Fractional flow of water

$r \quad$ radius

W $\quad$ pore opening width 


$\begin{array}{ll}h & \text { height } \\ n & \text { pore concentration } \\ l & \text { lever } \\ \mathrm{g} & \text { gravity acceleration }\end{array}$

Greek letters

$\varphi \quad$ Porosity

$\Phi \quad$ Dimensionless porosity

$\alpha \quad$ Corey's exponent

$\beta \quad$ Formation damage coefficient

$\chi \quad$ Correction coefficient for the lifting force

$\omega \quad$ Correction coefficient for hydrodynamic drag

$\sigma \quad$ Retention/concentration of deposited particles

$\varepsilon \quad$ Erosion number

$\xi \quad X / T$

\section{Subscripts}

$i \quad i$ th layer

$o \quad$ Oil

or Residual oil

w Water

wi Irreducible Water

$r \quad$ relative

$x \quad$ Direction along a reservoir 
Z Direction orthogonal to a reservoir

$0 \quad$ Reference variables

s particles/fines

$\mathrm{p} \quad$ pores

c internal cake

d hydrodynamic drag

n normal

$1 \quad$ lifting

e electrostatic

g gravity

cr critical

str straining

ini initial

\section{References}

Al-Abduwani, F.A.H., Bedrikovetsky, P. and R. Farajzadeh, 2005. External Filter Cake Erosion: Mathematical Model and Experimental Study SPE European Formation Damage Conference. Society of Petroleum Engineers Sheveningen, The Netherlands.

Bachman, R.C., Harding, T.G., Settari, A.T. and Walters, D.A., 2003. Coupled Simulation of Reservoir Flow, Geomechanics, and Formation Plugging With Application to High-Rate Produced Water Reinjection, SPE Reservoir Simulation Symposium. SPE, Houston, Texas.

Barenblatt, G.I., Entov, V.M. and Ryzhik, V.M., 1990. Theory Of Fluid Flows Through Natural Rocks Springer, Dordrecht.

Barenblatt, G.I., Patzek, T.W. and Silin, D.B., 2003. The Mathematical Model of Nonequilibrium Effects in Water-Oil Displacement. SPE Journal, 8(4): 409-416. 
Bedrikovetsky, P., 1993. Mathematical Theory of Oil and Gas Recovery (With Applications to ex-USSR Oil and Gas Fields). Petroleum Engineering and Development Studies.

Bedrikovetsky, P., Siqueira, F., Furtado, C. and Souza, A., 2010. Modified Particle Detachment Model for Colloidal Transport in Porous Media. Transport in Porous Media: 1-31.

Bergendahl, J. and Grasso, D., 2000. Prediction of colloid detachment in a model porous media: hydrodynamics. Chemical Engineering Science, 55(9): 1523-1532.

Bernard, G.G., 1967. Effect of Floodwater Salinity on Recovery Of Oil from Cores Containing Clays SPE California Regional Meeting, Los Angeles, California.

Bradford, S.A., Simunek, J., Bettahar, M., Van Genuchten, M.T. and Yates, S.R., 2003. Modeling colloid attachment, straining, and exclusion in saturated porous media. Environ Sci Technol, 37(10): 2242-50.

Bradford, S.A., Simunek, J. and Walker, S.L., 2006. Transport and straining of E. coli O157:H7 in saturated porous media. Water Resour. Res., 42(12): W12S12.

Bradford, S.A. et al., 2009. Modeling the coupled effects of pore space geometry and velocity on colloid transport and retention. Water Resour. Res., 45(2): W02414.

Corey, A.T. and Rathjens, C.H., 1956. Effect of Stratification on Relative Permeability Journal of Petroleum Technology, 8(12): 69-71.

Dullien, F.A.L., 1992. Porous Media: Fluid Transport and Pore Structure. Academic Press, New York.

Fauré, M.-H., Sardin, M. and Vitorge, P., 1997. Release of clay particles from an unconsolidated clay-sand core: experiments and modelling. Journal of Contaminant Hydrology, 26(1-4): 169-178.

Fogden, A., Kumar, M., Morrow, N.R. and Buckley, J.S., 2011. Mobilization of Fine Particles during Flooding of Sandstones and Possible Relations to Enhanced Oil Recovery. Energy \& Fuels: null-null.

Grolimund, D. and Borkovec, M., 2001. Release and Transport of Colloidal Particles in Natural Porous Media 1. Modeling. Water Resour. Res., 37(3): 559-570.

Jiao, D. and Sharma, M.M., 1994. Mechanism of Cake Buildup in Crossflow Filtration of Colloidal Suspensions. Journal of Colloid and Interface Science, 162(2): 454-462.

Kovscek, A.R., Wong, H. and Radke, C.J., 1993. A pore-level scenario for the development of mixed wettability in oil reservoirs. AIChE Journal, 39(6): 1072-1085.

Landau, L.D. and Lifshitz, E.M., 1987. Fluid Mechanics (Course of Theoretical Physics). Pergamon Press, Oxford.

Lemon, P., Zeini Jahromi, A., Bedrikovetsky, P. and Shahin, I., 2011. Effects of Injected Water Chemistry on Waterflood Sweep Efficiency Via Induced Fines Migration, SPE International Symposium on Oilfield Chemistry, Woodlands, Texas. 
Lever, A. and Dawe, R.A., 1984. Water-sensitivity and migration of fines in the Hopeman sandstone. Journal of Petroleum Geology, 7(1): 97-107.

Lever, A. and Dawe, R.A., 1987. Clay migration and entrapment in synthetic porous media. Marine and Petroleum Geology, 4(2): 112-118.

Mohan, K.K., Vaidya, R.N., Reed, M.G. and Fogler, H.S., 1993. Water sensitivity of sandstones containing swelling and non-swelling clays. Colloids and Surfaces A: Physicochemical and Engineering Aspects, 73: 237-254.

Mojarad, R.S. and Settari, A.T., 2007. Coupled Numerical Simulation of Reservoir Flow With Formation Plugging. Journal of Canadian Petroleum Technology, 46(3): 54-59.

Mungan, N., 1965. Permeability Reduction Through Changes in pH and Salinity. Journal of Petroleum Technology, 17(12): 1449-1453.

Ochi, J. and Vernoux, J.-F., 1998. Permeability decrease in sandstone reservoirs by fluid injection: Hydrodynamic and chemical effects. Journal of Hydrology, 208(3-4): 237-248.

Pang, S. and Sharma, M.M., 1997. A Model for Predicting Injectivity Decline in Water-Injection Wells SPE Formation Evaluation, 12(3): 194-201.

Rivet, S.M., Lake, L.W. and Pope, G.A., 2010. A Coreflood Investigation of Low-Salinity Enhanced Oil Recovery, SPE Annual Technical Conference and Exhibition. SPE, Florence, Italy.

Ryan, J.N. and Gschwend, P.M., 1994. Effect of Solution Chemistry on Clay Colloid Release from an Iron OxideCoated Aquifer Sand. Environmental Science \& Technology, 28(9): 1717-1726.

Schembre, J.M. and Kovscek, A.R., 2004. Thermally Induced Fines Mobilization: Its Relationship to Wettability and Formation Damage, SPE International Thermal Operations and Heavy Oil Symposium and Western Regional Meeting. Bakersfield, California.

Shapiro, A., Bedrikovetsky, P., Santos, A. and Medvedev, O., 2007. A stochastic model for filtration of particulate suspensions with incomplete pore plugging. Transport in Porous Media, 67(1): 135-164.

Shapiro, A.A. and Bedrikovetsky, P.G., 2010. A stochastic theory for deep bed filtration accounting for dispersion and size distributions. Physica A: Statistical Mechanics and its Applications, 389(13): 2473-2494.

Shapiro, A.A. and Stenby, E.H., 2000. Factorization of Transport Coefficients in Macroporous Media. Transport in Porous Media, 41(3): 305-323.

Sharma, M.M. and Yortsos, Y.C., 1987. Fines migration in porous media. AIChE Journal, 33(10): 1654-1662.

Tang, G.-Q. and Morrow, N.R., 1999. Influence of brine composition and fines migration on crude oil/brine/rock interactions and oil recovery. Journal of Petroleum Science and Engineering, 24(2-4): 99-111. 
Torkzaban, S., Bradford, S.A. and Walker, S.L., 2007. Resolving the coupled effects of hydrodynamics and DLVO forces on colloid attachment in porous media. Langmuir, 23(19): 9652-60.

Valdya, R.N. and Fogler, H.S., 1992. Fines Migration and Formation Damage: Influence of pH and Ion Exchange. SPE Production Engineering, 7(4): 325-330.

Yildiz, H.O. and Morrow, N.R., 1996. Effect of brine composition on recovery of Moutray crude oil by waterflooding. Journal of Petroleum Science and Engineering, 14(3-4): 159-168.

Yortsos, Y.C., 1995. A theoretical analysis of vertical flow equilibrium. Transport in Porous Media, 18(2): 107-129.

Yuan, H. and Shapiro, A.A., 2010. Modeling non-Fickian transport and hyperexponential deposition for deep bed filtration. Chemical Engineering Journal, 162(3): 974-988.

Yuan, H. and Shapiro, A.A., 2011. A mathematical model for non-monotonic deposition profiles in deep bed filtration systems. Chemical Engineering Journal, 166(1): 105-115.

Zeinijahromi, A., Lemon, P. and Bedrikovetsky, P., 2011. Effects of Induced Migration of Fines on Water Cut during Waterflooding, SPE Middle East Oil and Gas Show and Conference. SPE, Manama.

Zhang, X., Shapiro, A. and Stenby, E., 2011. Upscaling of Two-Phase Immiscible Flows in Communicating Stratified Reservoirs. Transport in Porous Media: 1-26.

Zinati, F.F., Farajzadeh, R., Currie, P.K. and Zitha, P.L.J., 2007. Modeling of External Filter-Cake Buildup in Radial Geometry, European Formation Damage Conference. Society of Petroleum Engineers, Scheveningen, The Netherlands.

\section{Appendix A: Upscaling model for waterflooding in communicating layer-cake reservoirs}

In this appendix, the upscaling method in Refs. (Yortsos, 1995; Zhang et al., 2011) for waterflooding in communicating layer cake reservoirs are introduced in details. It is assumed that a stratified reservoir has a span $L$ in the horizontal $x$ direction and a thickness of $H$ in the vertical $z$ direction. The reservoir consists of $N$ communicating horizontal layers. Water is injected horizontally to displace oil in place. Provided that the water saturation is $s(x, z, t)$, the mass balance equation for water can be written as (Bedrikovetsky, 1993) 


$$
\varphi \frac{\partial s}{\partial t}+\frac{\partial f(s) U_{x}}{\partial x}+\frac{\partial f(s) U_{z}}{\partial z}=0
$$

where $\varphi$ is the porosity, $f$ is the fractional flow function of water, $U_{x}$ is the Darcy's velocity in $\mathrm{x}$ direction and the $U_{z}$ is the Darcy's velocity in $z$ direction. The impacts of gravity and capillary forces are neglected. The velocities can be expressed in terms of the pressure gradient according to Darcy's law:

$$
U_{x}=-\lambda_{x} \frac{\partial p}{\partial x}, U_{z}=-\lambda_{z} \frac{\partial p}{\partial z}
$$

where the mobilities $\lambda_{x}, \lambda_{z}$ and the fractional flow function are:

$$
\lambda_{x}=k_{x}\left(\frac{k_{r w}}{\mu_{w}}+\frac{k_{r o}}{\mu_{o}}\right), \lambda_{z}=k_{z}\left(\frac{k_{r w}}{\mu_{w}}+\frac{k_{r o}}{\mu_{o}}\right), f(s)=\frac{k_{r w} / \mu_{w}}{k_{r w} / \mu_{w}+k_{r o} / \mu_{o}}
$$

where $k_{r w}$ is the relative permeability of water, $k_{r o}$ is the relative permeability of oil, $\mu_{w}$ is the water's viscosity, and $\mu_{o}$ is the oil's viscosity. Here Corey's correlations for relative permeabilities are adopted (Corey and Rathjens, 1956):

$$
k_{r w}=k_{r w o r}\left(\frac{s-s_{w i}}{1-s_{o r}-s_{w i}}\right)^{\alpha_{w}}, \quad k_{r o}=k_{r o w i}\left(\frac{1-s-s_{o r}}{1-s_{o r}-s_{w i}}\right)^{\alpha_{o}}
$$

where $s_{o r}$ and $s_{w i}$ are the residual oil saturation and irreducible water saturation, $k_{r w o r}$ and $k_{r o w i}$ are the relative permeabilities of water and oil at $s_{o r}$ and $s_{w i}, \alpha_{w}$ and $\alpha_{o}$ are the so-called Corey's exponents for water and oil respectively.

The permeability, porosity, the mobility of each layer may be rescaled as follows: 


$$
\begin{aligned}
& \langle\varphi\rangle=\frac{1}{H} \int_{0}^{H} \varphi d z, \quad \Phi=\frac{\varphi}{\langle\varphi\rangle} ; \quad\left\langle k_{x}\right\rangle=\frac{1}{H} \int_{0}^{H} k_{x} d z, \quad K=\frac{k_{x}}{\left\langle k_{x}\right\rangle} ; \\
& \left\langle\lambda_{x}\right\rangle=\frac{1}{H} \int_{0}^{H} \lambda_{x} d z, \quad \Lambda_{x}=\frac{\lambda_{x}}{\lambda_{0}}, \quad\left\langle\lambda_{x}\right\rangle=\frac{\left\langle\lambda_{x}\right\rangle}{\lambda_{0}}, \quad \lambda_{0}=\frac{\left\langle k_{x}\right\rangle k_{\text {rowi }}}{\mu_{o}} ;
\end{aligned}
$$

The only assumption in the model is that the pressure gradient in vertical direction may be negligible compared to the horizontal pressure drop. Asymptotic analysis resulting in this assumption is carried out by Yortsos (1995), and Zhang et al. (2011). Such an assumption gives rise to $\frac{\partial}{\partial z}\left(\frac{\partial p}{\partial x}\right)=0$, which in sequence leads to:

$$
\left\langle U_{x}\right\rangle=-\frac{1}{H} \int_{0}^{H} \lambda_{x} \frac{\partial p}{\partial x} d z=-\frac{\partial p}{\partial x}\left\langle\lambda_{x}\right\rangle
$$

Substitution of the average mobility in the $\mathrm{x}$ direction from Eq. (A-5) into Eq. (A-6) leads to:

$$
U_{x}=\frac{\lambda_{x}}{\left\langle\lambda_{x}\right\rangle}\left\langle U_{x}\right\rangle
$$

Due to the assumption of incompressibility of fluids, the mass conservation law for the overall

fluid velocity has the form of

$$
\frac{\partial U_{x}}{\partial x}+\frac{\partial U_{z}}{\partial z}=0
$$

Substitution of Eq. (A-7) into Eq. (A-8) leads to the following expression for $U_{z}$ :

$$
U_{z}=-\int_{0}^{z} \frac{\partial U_{x}}{\partial x} d z=-\left\langle U_{x}\right\rangle \frac{\partial}{\partial x}\left(\frac{\int_{0}^{z} \lambda_{x} d z}{\left\langle\lambda_{x}\right\rangle}\right)
$$

Finally, substitution of Eq. (A-7) and Eq. (A-9) back into Eq. (A-1) leads to: 


$$
\varphi \frac{\partial s}{\partial t}+\left\langle U_{x}\right\rangle \frac{\partial}{\partial x}\left(\frac{f \lambda_{x}}{\left\langle\lambda_{x}\right\rangle}\right)-\left\langle U_{x}\right\rangle \frac{\partial}{\partial z}\left[f \frac{\partial}{\partial x}\left(\frac{\int_{0}^{z} \lambda_{x} d z}{\left\langle\lambda_{x}\right\rangle}\right)\right]=0
$$

Eq. (A-10) may take the following dimensionless form:

$$
\Phi \frac{\partial s}{\partial T}+\frac{\partial}{\partial X}\left(\frac{f \Lambda_{x}}{\left\langle\Lambda_{x}\right\rangle}\right)-\frac{\partial}{\partial Z}\left[f \frac{\partial}{\partial X}\left(\frac{\int_{0}^{Z} \Lambda_{x} d Z}{\left\langle\Lambda_{x}\right\rangle}\right)\right]=0
$$

where the dimension variables in Eq. (A-12) are adopted.

$$
\Phi=\frac{\varphi}{\langle\varphi\rangle}, \quad X=\frac{x}{L}, \quad Z=\frac{z}{H}, \quad T=\frac{t}{\langle\varphi\rangle L /\left\langle U_{x}\right\rangle}
$$

Eq. (A-11) is a two-dimensional partial integro-differential equation involving multiple integral operators. Solving such an equation usually requires intensive computational efforts. The 2-D equation can be converted into a series of equations, each of which represents the mass balance in a layer. The system of equations takes the following form (the details are given in Ref. (Zhang et al., 2011)):

$$
\Phi_{i} \frac{\partial s_{i}}{\partial T}-\frac{\partial}{\partial X}\left(f_{i} \frac{B_{i}-B_{i-1}}{\Delta Z_{i} B_{N}}\right)+\frac{1}{\Delta Z_{i}}\left[G_{i-1} \frac{\partial}{\partial X}\left(\frac{B_{i-1}}{B_{N}}\right)-G_{i} \frac{\partial}{\partial X}\left(\frac{B_{i}}{B_{N}}\right)\right]=0
$$

where indices $i$ and $j$ represent the $i$ th layer. $B_{i}$ and $G_{i}$ are expressed as:

$$
\begin{aligned}
& G_{i}=f_{i}\left[\frac{\partial}{\partial X}\left(\frac{B_{i}}{B_{N}}\right)<0\right]+f_{i+1}\left[\frac{\partial}{\partial X}\left(\frac{B_{i}}{B_{N}}\right)>0\right], \quad i \in[1, N-1] \\
& G_{N}=0, \quad B_{i}=\sum_{j}^{i} \Delta Z_{j} \Lambda_{j}
\end{aligned}
$$


Here the result of logic operators [o] is one if expression $\circ$ is true, and zero if it is false. The injection boundary condition is $1-s_{o r}$ corresponding to the maximum water saturation while the initial condition is $s_{w i}$. For model calculations below we assume that the residual saturations are the same for all the layers.

\section{Appendix B: Maximum retention function of attached reservoir fines}

In this appendix, the expression of the maximum retention function for a cylinder capillary is introduced. The underlying torque balance analysis follows Bedrikovetsky et al.(2010). Similar approach was utilized for estimation of external filter cake thickness in the fractured and openhole wells (Al-Abduwani et al., 2005; Zinati et al., 2007). The porous space is assumed to be a bunch of parallel rectangular pores with the Hele-Shaw flow occurring between the walls (Landau and Lifshitz, 1987). Porosity and permeability can be expressed via the pore opening (width) $W$ and pore concentration $n$ (Dullien, 1992):

$$
\varphi=n W^{2} ; \quad k_{0}=\frac{n W^{4}}{8 \pi}
$$

It allows for the calculation of pore opening and concentration for known porosity and permeability:

$$
W=\sqrt{\frac{8 \pi k_{0}}{\varphi}} ; \quad n=\frac{\varphi^{2}}{8 \pi k_{0}}
$$

Following Bedrikovetsky et al. (2010), the balance between the torques of the hydrodynamic drag, the lifting force, gravity/buoyancy and the electrostatic force can be expressed as: 


$$
F_{e}+\frac{4}{3} \pi r_{s}^{3} \Delta \rho g-\chi r_{s}^{3} \sqrt{\frac{\rho_{w} \mu_{w} U^{3}}{\varphi^{3}\left(W-2 h_{c}\right)^{3}}}=\frac{l_{d}}{l_{n}} \frac{\omega \pi \mu_{w} r_{s}^{2} U}{\varphi\left(W-2 h_{c}\right)}
$$

where $F_{e}$ is maximum value of electrostatic DLVO force, $r_{s}$ is the particle radius, $\Delta \rho$ is the density difference between the solid particle and water, $\chi$ is the correction coefficient for the lifting force, $h_{c}$ is the height of internal cake, $\omega$ is the correction coefficient for hydrodynamic drag. The lever ratio for the drag force to the normal force $l_{d} / l_{n}=\sqrt{3}$.

Introducing a new dimensionless variable:

$$
y=\frac{\mu_{w} r_{s}^{2} U}{\varphi H\left(1-2 h_{c} / W\right) F_{e}}
$$

leads to the following form of the previous equation:

$$
1+\frac{4 \pi r_{s}^{3}}{3 F_{e}} \Delta \rho g-\frac{\chi \sqrt{\rho_{w} F_{e}}}{\mu_{w}} y^{\frac{3}{2}}=\sqrt{3} \omega \pi y
$$

For the rectangular shape of pores, the critical retention concentration is calculated via the properties of the internal cake:

$$
\sigma_{c r}=\left[W^{2}-\left(W-h_{c}\right)^{2}\right]\left(1-\varphi_{c}\right) n
$$

Substitution of the $W^{2}$ in Eq. (B-1) into (B-6) leads to:

$$
\sigma_{c r}=\left[1-\left(1-\frac{h_{c}}{W}\right)^{2}\right]\left(1-\varphi_{c}\right) \varphi
$$

Let us express the equilibrium cake thickness via $y$ from Eq. (B-4): 


$$
\frac{h_{c}}{W}=\frac{1}{2}-\frac{\mu_{w} r_{s}^{2} U}{2 y \varphi W F_{e}}
$$

Substitution of (B-8) into (B-7) leads to the final expression of the critical retention concentration:

$$
\sigma_{c r}=\left[1-\left(\frac{\mu_{w} r_{s}^{2} U}{\varphi W F_{e} y}\right)^{2}\right]\left(1-\varphi_{c}\right) \varphi
$$

The root $y$ of cubic equation (B-5) is independent of velocity $U$. Thus, Eq. (B-9) provides with quadratic polynomial form of the critical retention function $\sigma_{c r}(U)$.

By assuming that the reservoir fines are only released in the water swept zones, and that the porous medium is water wetted, the hydrodynamic dragging force on the fines is only from the water phase. Eq. (B-9) can be rewritten for the case with two-phase flow:

$$
\sigma_{c r}=\left[1-\left(\frac{\mu_{w} r_{s}^{2} U f(s)}{s \varphi W F_{e} y}\right)^{2}\right]\left(1-\varphi_{c}\right) \varphi
$$

\section{Appendix C: Adaptation of waterflooding model}

In this appendix, the expressions of horizontal mobility and the fraction flow are altered to take into account the migration of fines and subsequent reduction of permeability. Similar to Eq. (4), the total mobility in the $i$ th layer and the fraction flow of water can be rewritten as:

$$
\Lambda_{x i}=\frac{K_{i}\left\langle k_{x}\right\rangle}{\lambda_{0}}\left(\frac{\lambda_{r w i}}{1+\beta \sigma_{s t r}}+\lambda_{r o i}\right), \quad f_{i}=\frac{\lambda_{r w i} /\left(1+\beta \sigma_{s t r}\right)}{\lambda_{r w i} /\left(1+\beta \sigma_{s t r}\right)+\lambda_{r o i}}
$$


Due to the assumption of instant straining of all released particles, the concentration of strained particles is equal to the initial deposition minus the maximum retention. The maximum retention is dependent on the local velocity of water, which leads to the dependence of strained retention on water velocity:

$$
\sigma_{s t r}=\sigma_{i n i}-\sigma_{c r}\left(\frac{\mu_{w} r_{s}^{2} f(s)}{s \sqrt{k_{x} \varphi} F_{n}} U_{i}\right)
$$

With the help of Eq. (A-7) and Eq.(A-9), the norm of the total velocity can be expressed as:

$$
U=\sqrt{U_{x}^{2}+U_{z}^{2}}=\left\langle U_{x}\right\rangle \sqrt{\left(\frac{\Lambda_{x}}{\left\langle\Lambda_{x}\right\rangle}\right)^{2}+\left[\frac{\partial}{\partial X}\left(\frac{\int_{0}^{Z} \Lambda_{x} d Z}{\left\langle\Lambda_{x}\right\rangle}\right)\right]^{2}}
$$

The velocity of water in the $i$ th layer can be further transformed by taking into account of (A-13):

$$
U_{i}=\left\langle U_{x}\right\rangle \sqrt{\left(\frac{B_{i}-B_{i-1}}{\Delta Z_{i} B_{N}}\right)^{2}+\left[\frac{\partial}{\partial X}\left(\frac{B_{i}}{B_{N}}\right)\right]^{2}}
$$




\section{Captions for Figures}

Fig. 1 Forces and torque balance for the particle attached to the internal cake surface

Fig. 2 Water saturation profiles at the top of the reservoir (a), in the center of the reservoir (b), and at the bottom of the reservoir (c).

Fig. 3 Averaged water saturation profiles $(\xi=\mathrm{X} / \mathrm{T})$ resulted from different values of $M$

Fig. 4 Water saturation profiles in the X-Z plane: (a). $\beta=0$; (b). $\beta=150$;

Fig. 5 Compare formation damage coefficients: (a). Water cut at the production site; (b).

Recovery factor

Fig. 6 Pressure drop between the injector and the producer

Fig. 7 Compare mobility ratios: (a). Water cut at the production site; (b). Recovery factor

Fig. 8 Increased recovery due to migration of fines (low salinity waterflooding) with different mobility ratios 


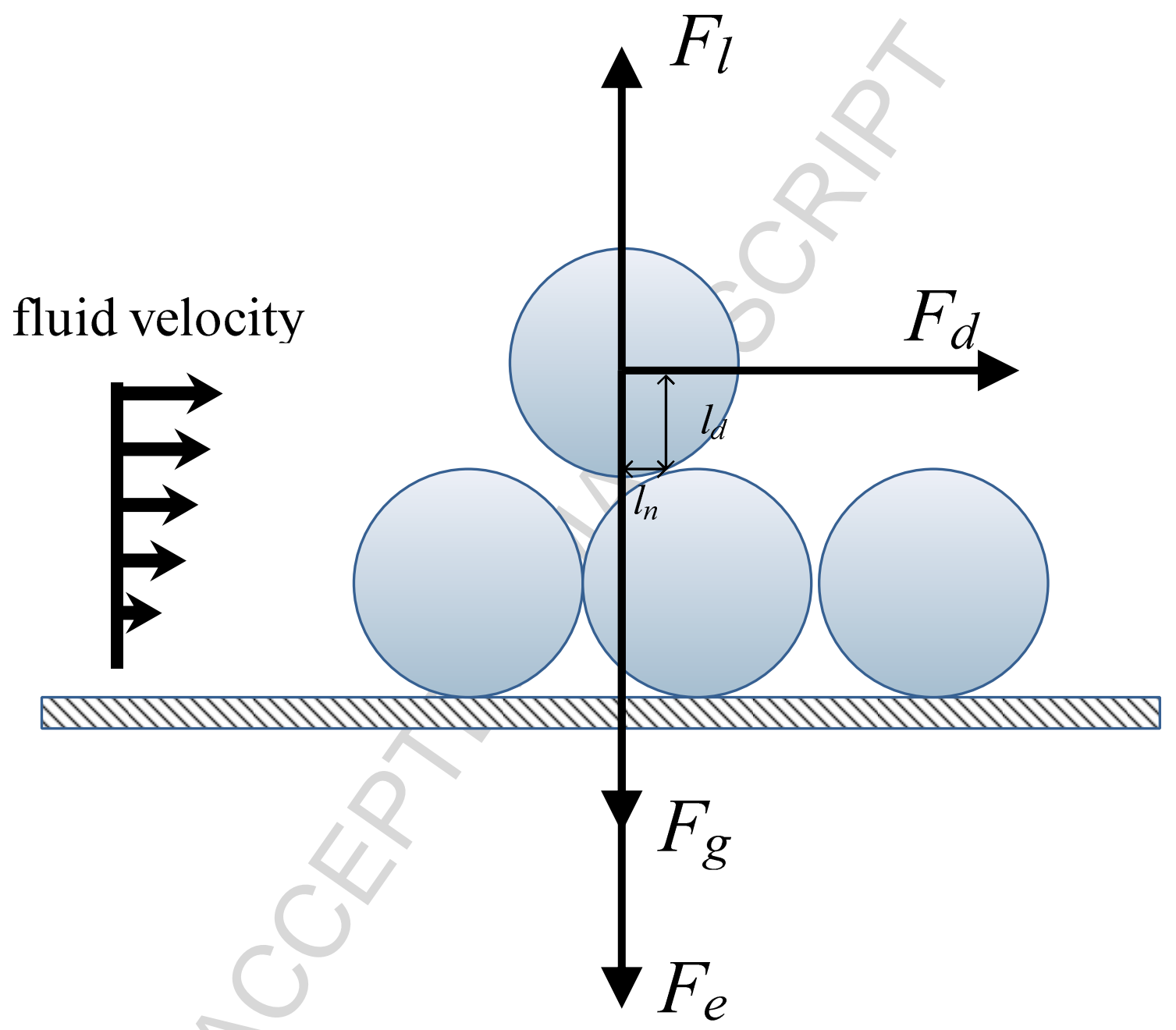

Fig. 1 

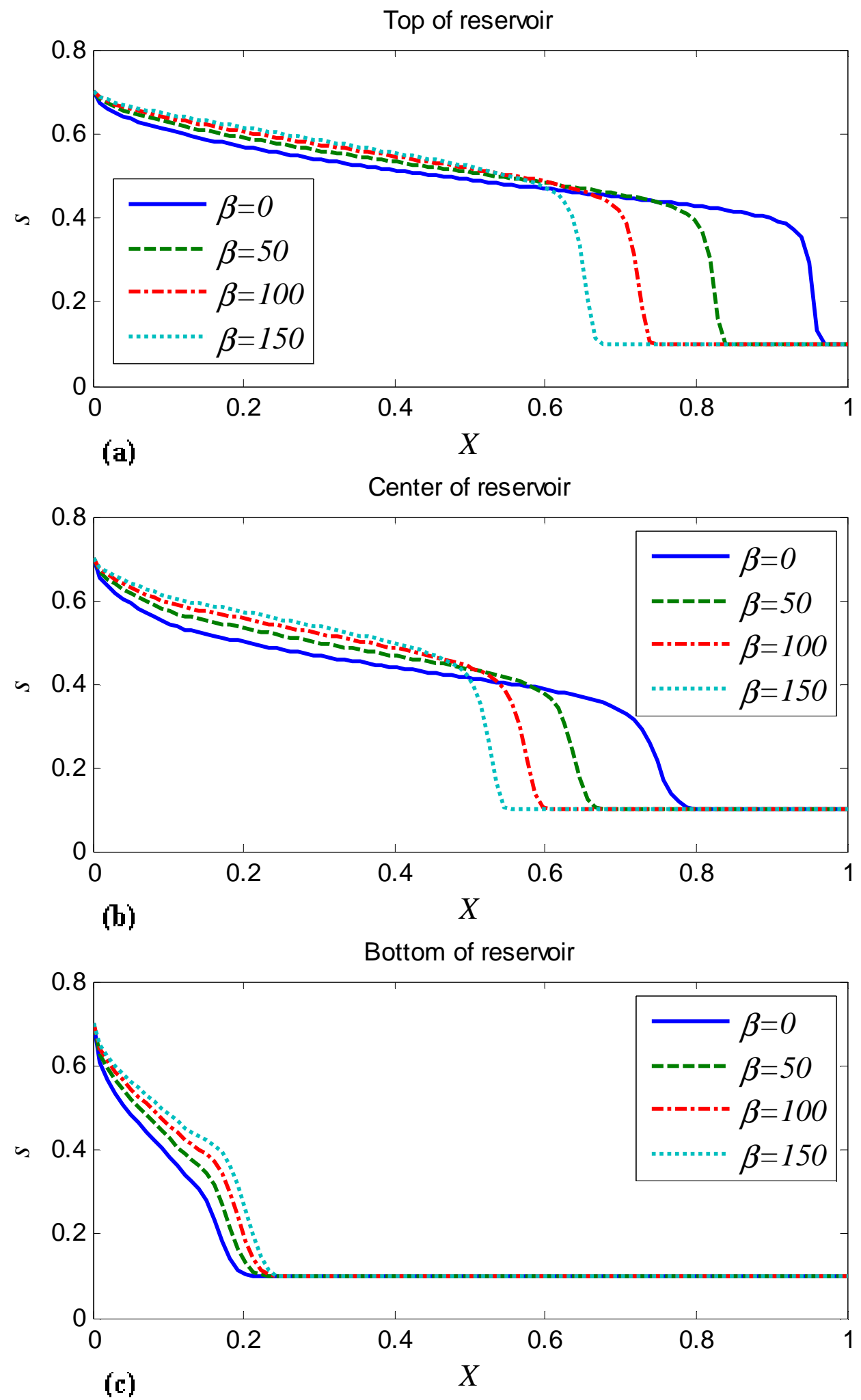

Fig. 2 
ACCEPTED MANUSCRIPT

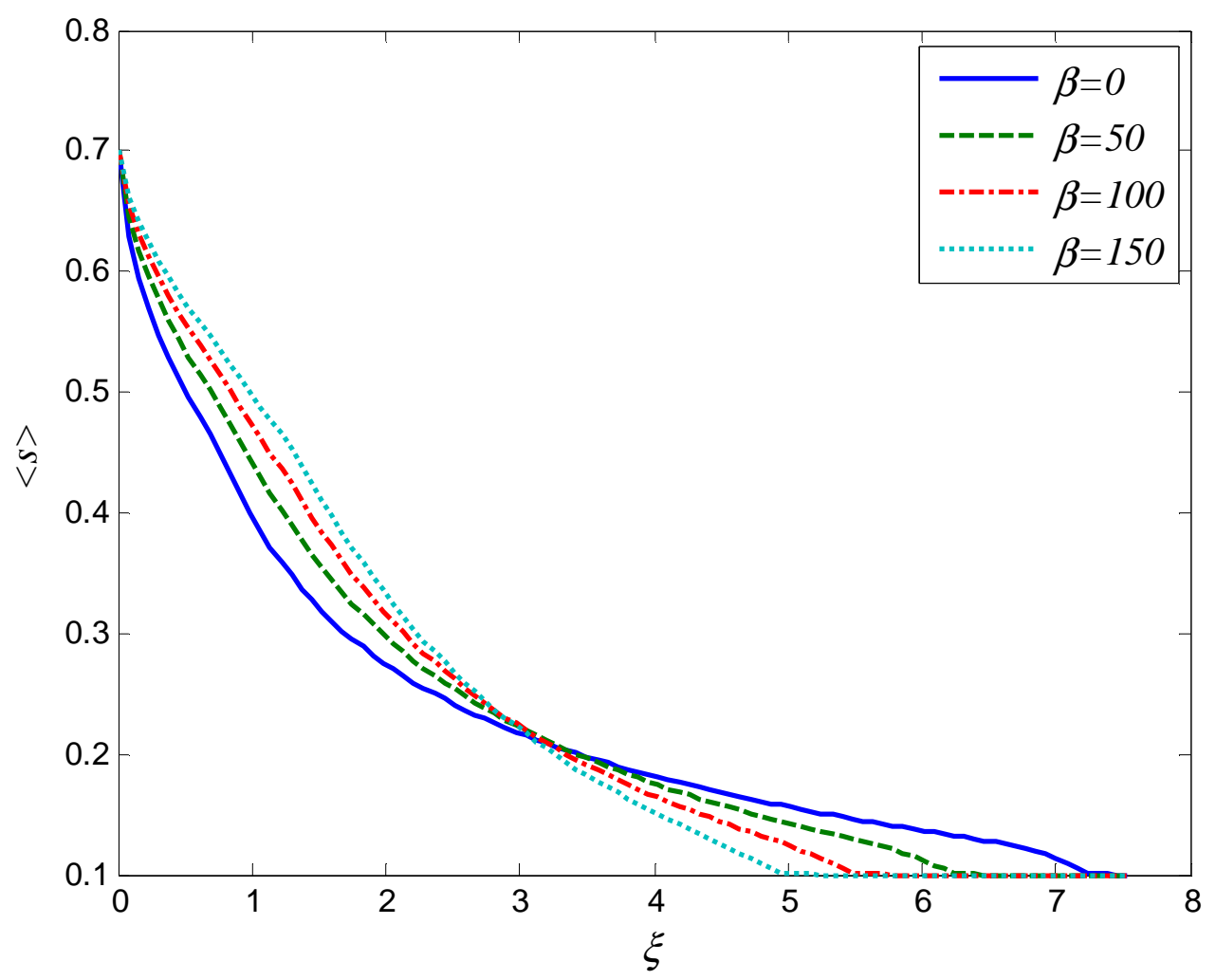

Fig. 3 

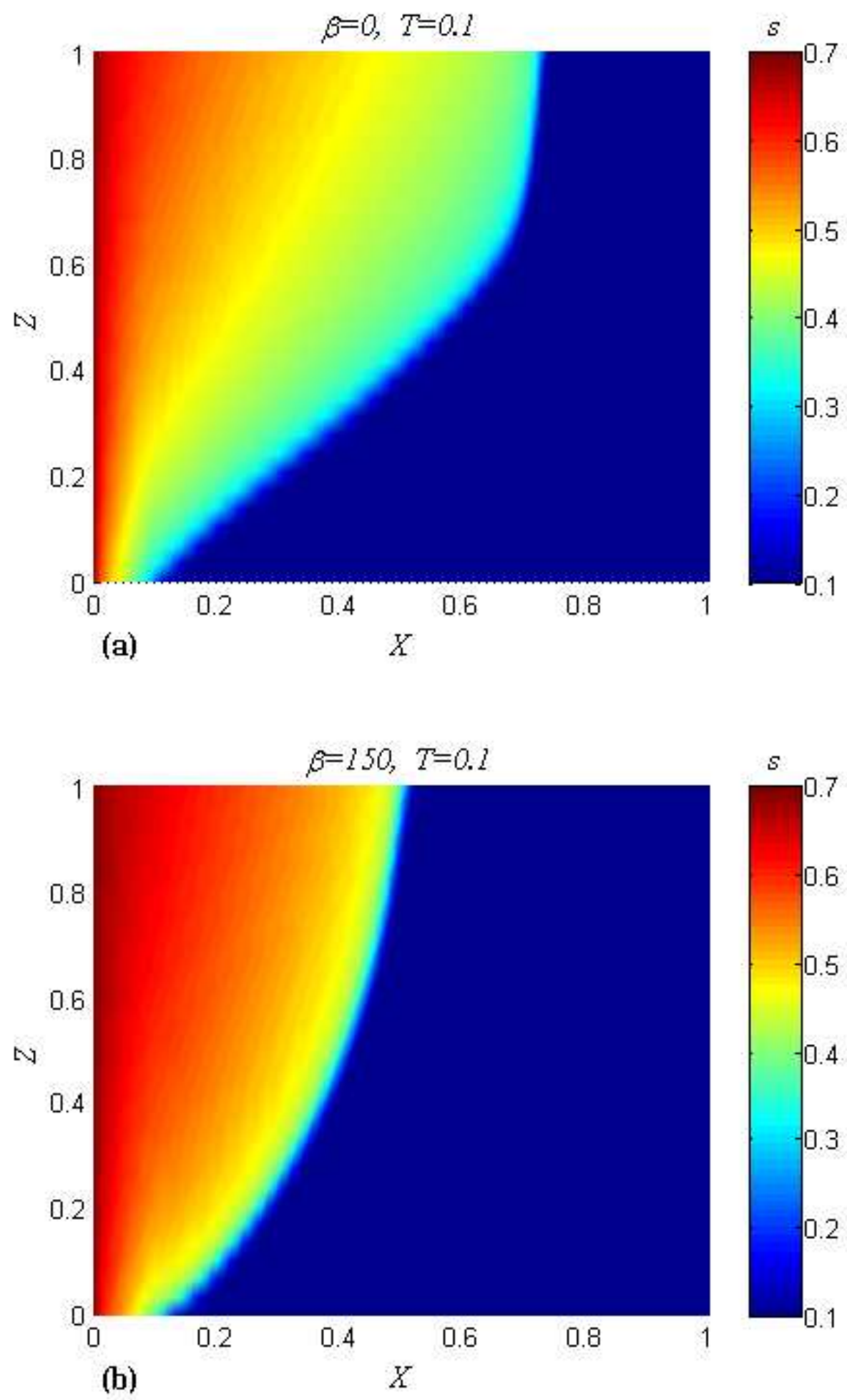

Fig. 4 

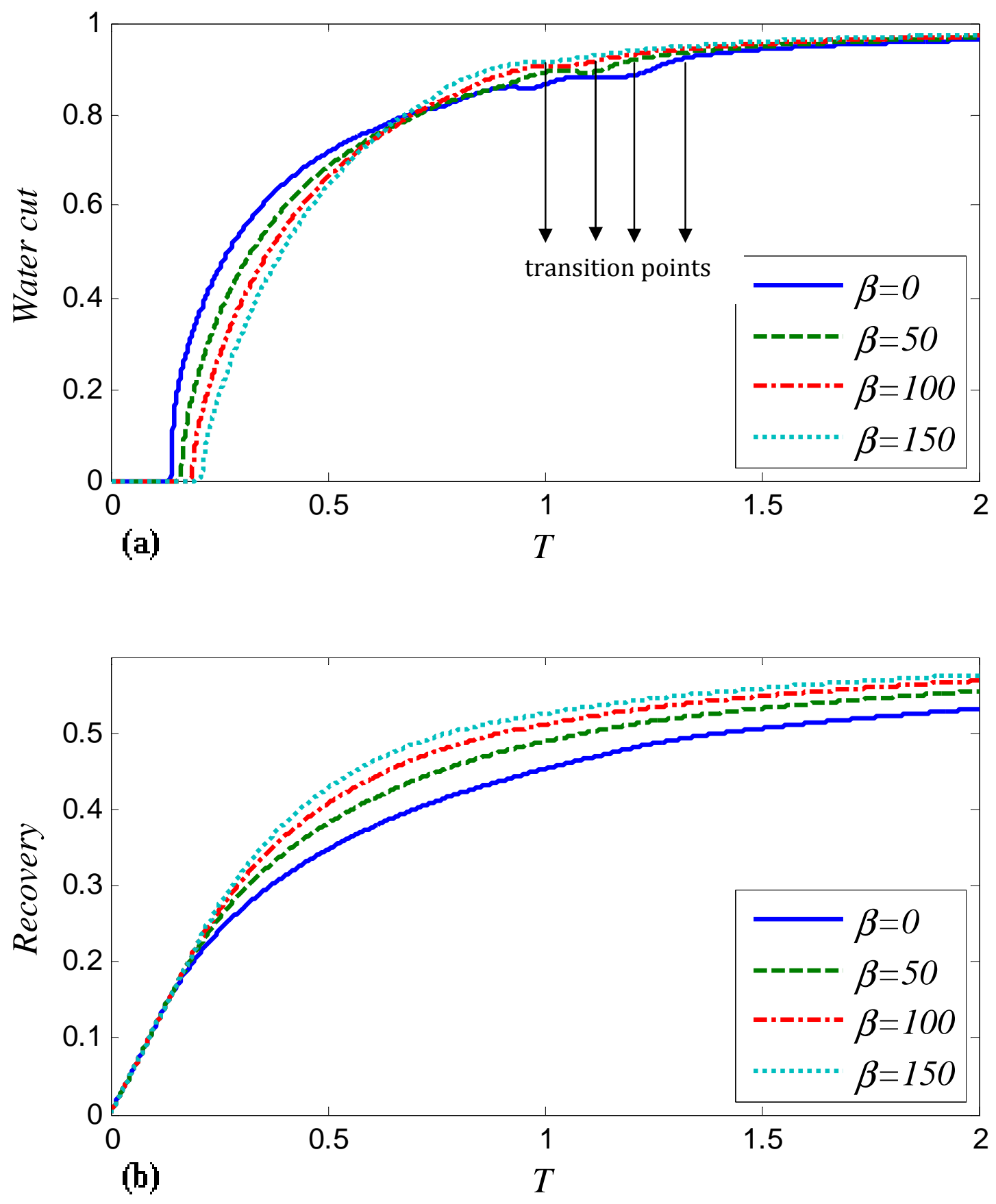

Fig. 5 


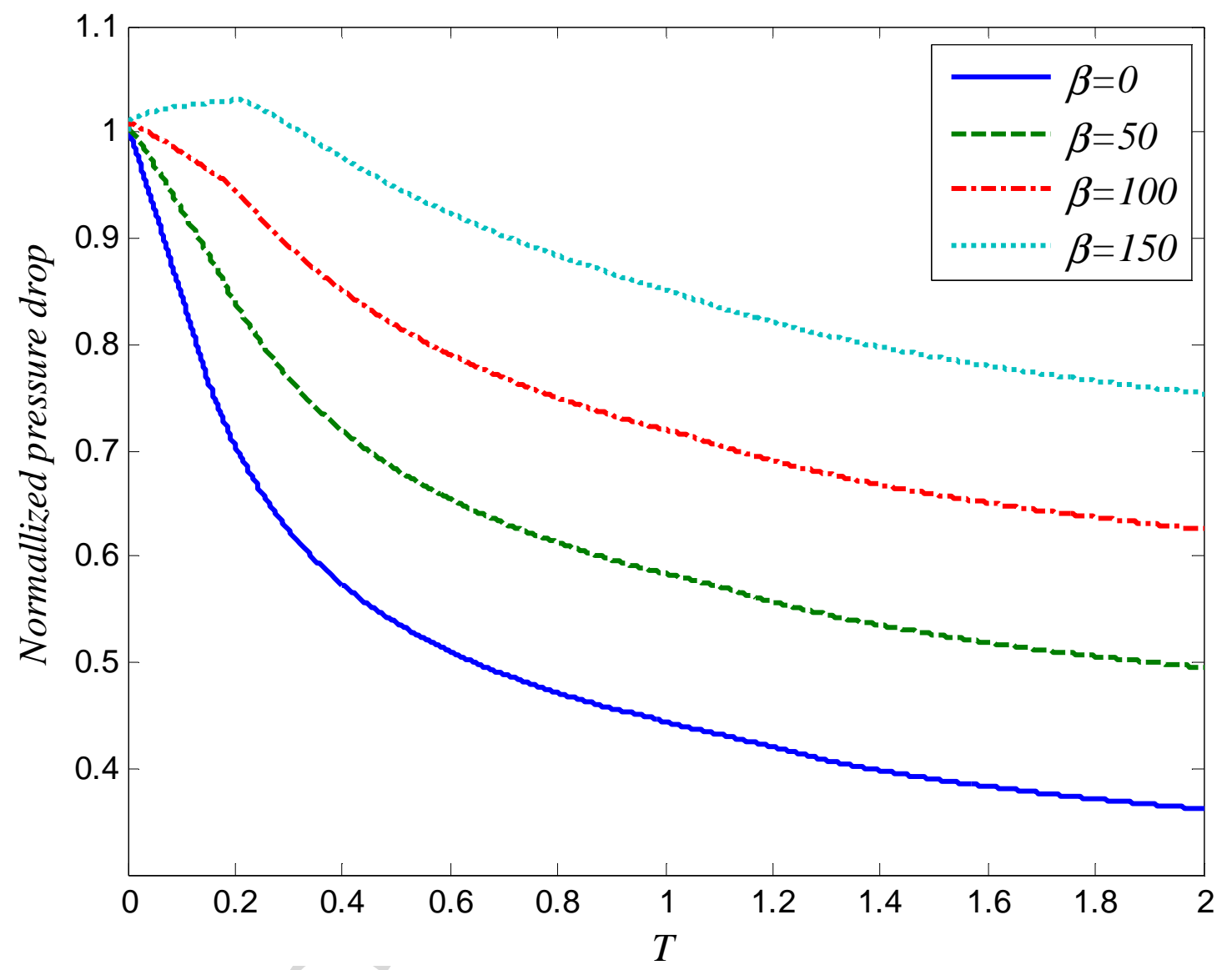

Fig. 6 


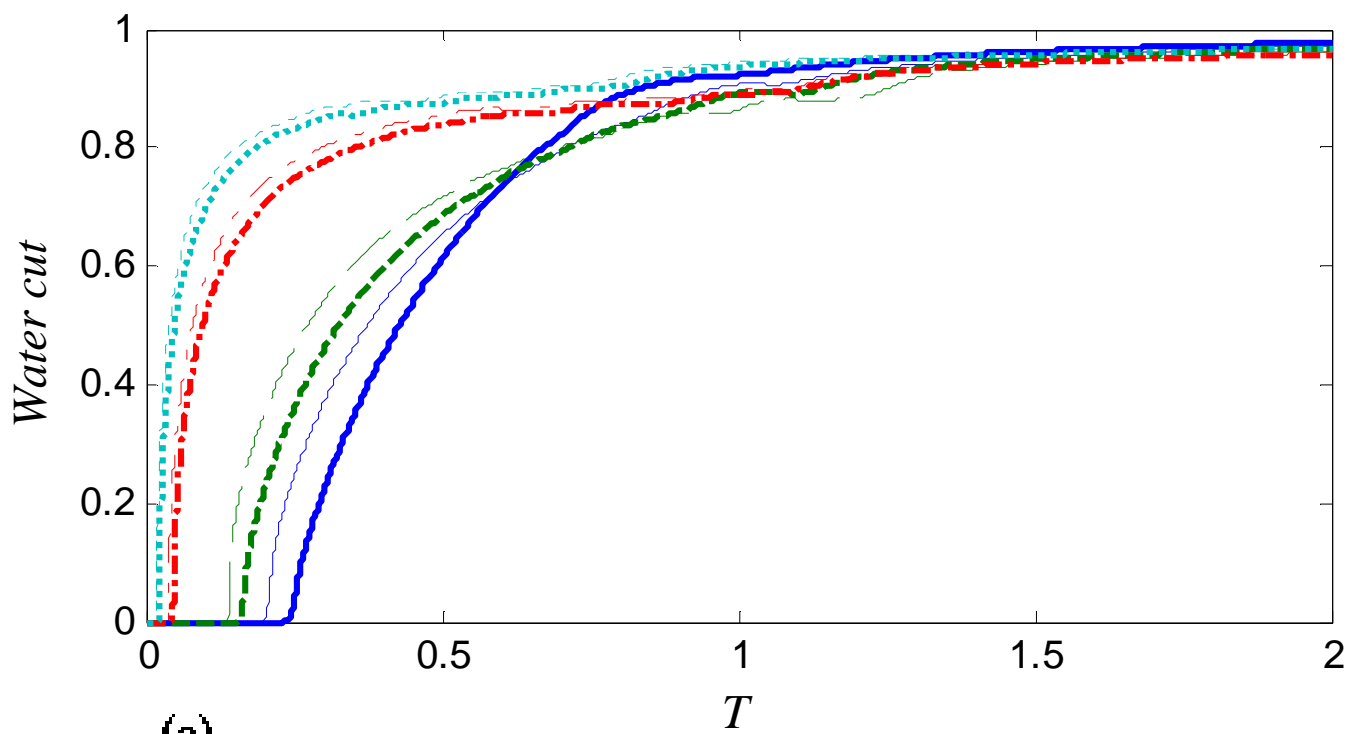

(a)

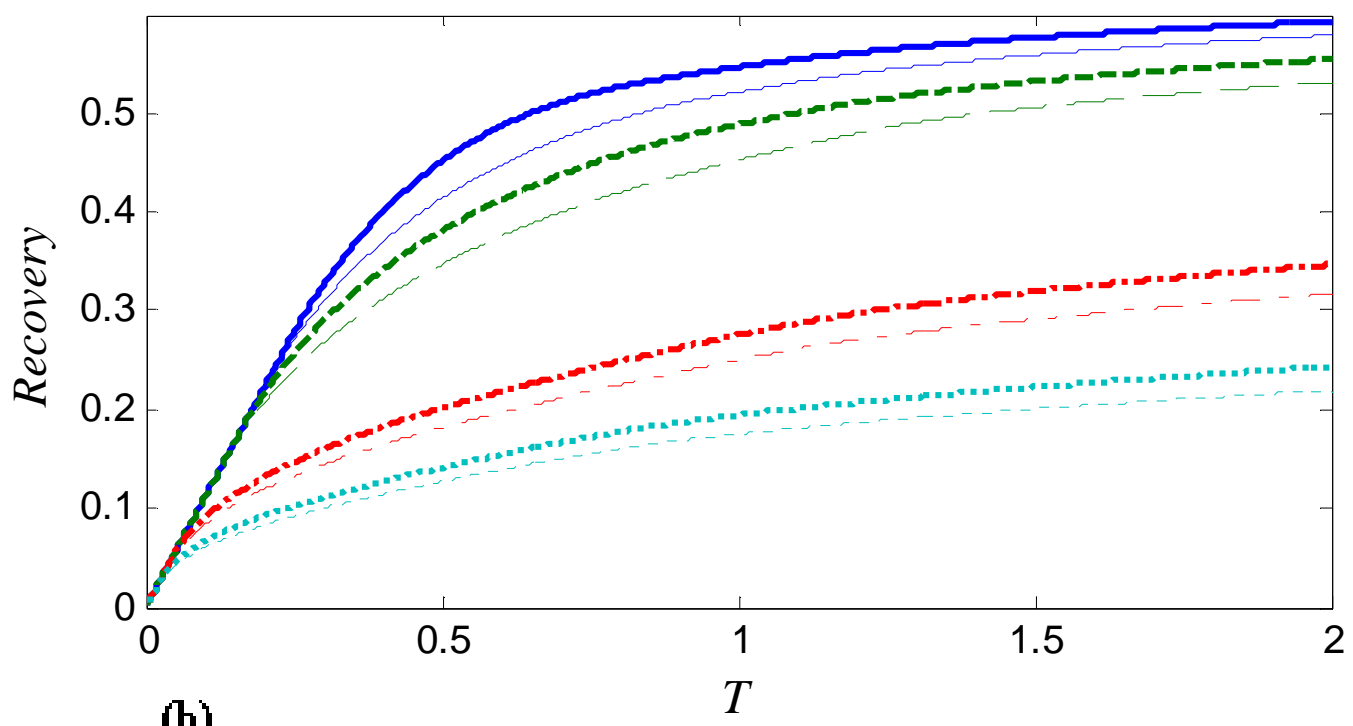

(b)

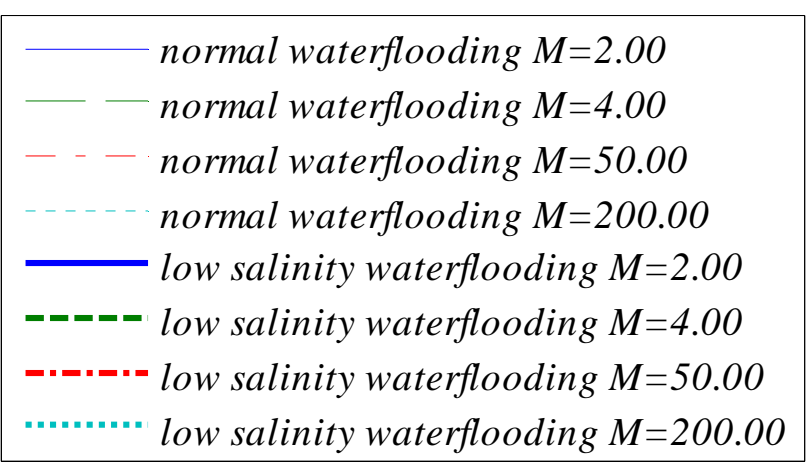

Fig. 7 

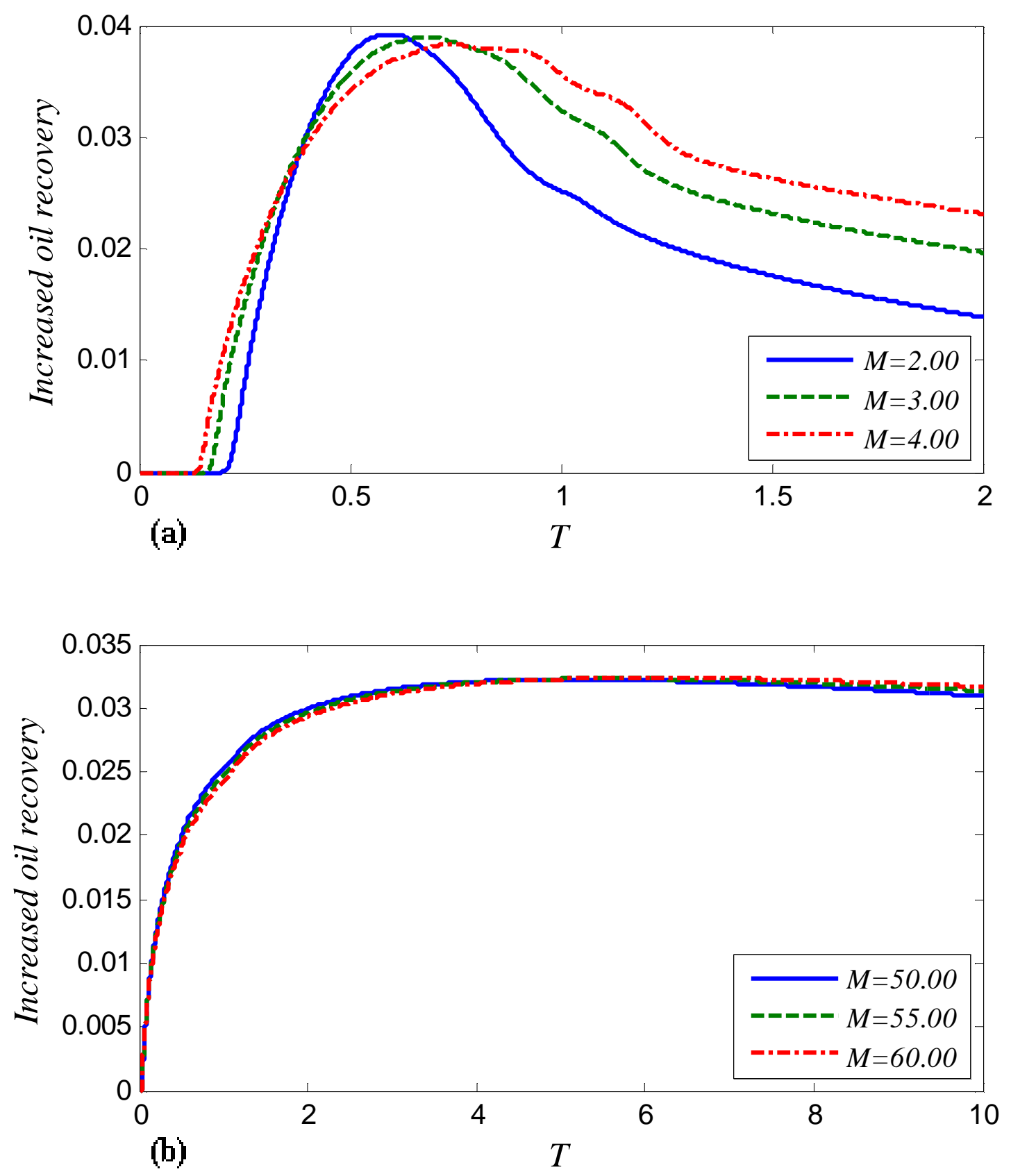

Fig. 8 


\section{Highlights}

$>$ The effects of fines migration induced by low salinity are incorporated into the model for waterflooding in a communicating layer cake reservoir. > Fines migration reduces permeability in water swept zones and diverts water flow to non-swept zones. > Water breakthrough is delayed and oil recovery is increased. >More energy for pressure drop is required to maintain a constant flow rate. > High water-oil mobility ratio facilitates the fluid diversion caused by fines migration. 